\title{
The ethical debate about the gig economy: a review and critical analysis
}

Zhi Ming Tan1, Nikita Aggarwal,2 Josh Cowls1,3, Jessica Morley1, Mariarosaria Taddeo1,3, Luciano Floridi $1,3, *$

1 Oxford Internet Institute, University of Oxford, 1 St Giles', Oxford, OX1 3JS, UK

2 Faculty of Law, University of Oxford, St. Cross Building, St. Cross Road, Oxford OX1 3UL, United Kingdom;

3 The Alan Turing Institute, British Library, 96 Euston Rd, London NW1 2DB, UK

*Email of correspondence author: luciano.floridi@oii.ox.ac.uk

\begin{abstract}
The gig economy is a phenomenon that is rapidly expanding, redefining the nature of work and contributing to a significant change in how contemporary economies are organised. Its expansion is not unproblematic. This article provides a clear and systematic analysis of the main ethical challenges caused by the gig economy. Following a brief overview of the gig economy, its scope and scale, we map the key ethical problems that it gives rise to, as they are discussed in the relevant literature. We map them onto three categories: the new organisation of work (what is done), the new nature of work (how it is done), and the new status of workers (who does it). We then evaluate a recent initiative from the EU that seeks to address the challenges of the gig economy. The 2019 report of the European High-Level Expert Group on the Impact of the Digital Transformation on EU Labour Markets is a positive step in the right direction. However, we argue that ethical concerns relating to algorithmic systems as mechanisms of control, and the discrimination, exclusion and disconnectedness faced by gig workers require further deliberation and policy response. A brief conclusion completes the analysis. The appendix presents the methodology underpinning our literature review.
\end{abstract}

\section{Keywords}

Algorithms; Digital Ethics; Digital Platforms; Digital Technologies; Gig Economy; Labour Market; Labour Rights. 


\section{Introduction}

In recent years, digital platforms that support on-demand (or 'gig') work have grown enormously and across an expanding range of industries and geographies. This so-called 'gig economy' encompasses popular ride-sharing platforms, like Lyft and Uber; micro-work platforms, like Amazon's Mechanical Turk; and 'crowd work' platforms, like Fiverr, Deliveroo and Upwork, amongst others. The gig economy is a significant and expanding phenomenon that is rapidly reshaping one of the most fundamental aspects of the economy and society: the labour market. Given the scope and depth of its impact, the gig economy also raises important ethical issues. This article analyses the nature and implications of these ethical issues through a systematised literature review (Grant and Booth 2009), in order to provide a stepping stone towards a better ethical framework for understanding and governing the gig economy.

The article is structured as follows. Section 2 begins with a high-level overview of the gig economy: its scope, scale and significance. Based on a review of the relevant literature, Sections 3 to 5 map the ethical debate relating to the gig economy onto three categories: the new organisation of work (what is done); the new nature of work (how it is done); and the new status of workers (who does it) (Figure 1). Each category is examined in detail. Section 6 evaluates the work on the gig economy carried out by a High-Level Expert Group (HLG) commissioned by the EU, as one of the most important policy initiatives to address the challenges of the gig economy. A short conclusion completes the analysis. In the appendix, we describe the methodology underpinning our literature review.

Figure 1: Main Categories of Ethical Debate and Key Concerns in the Gig Economy

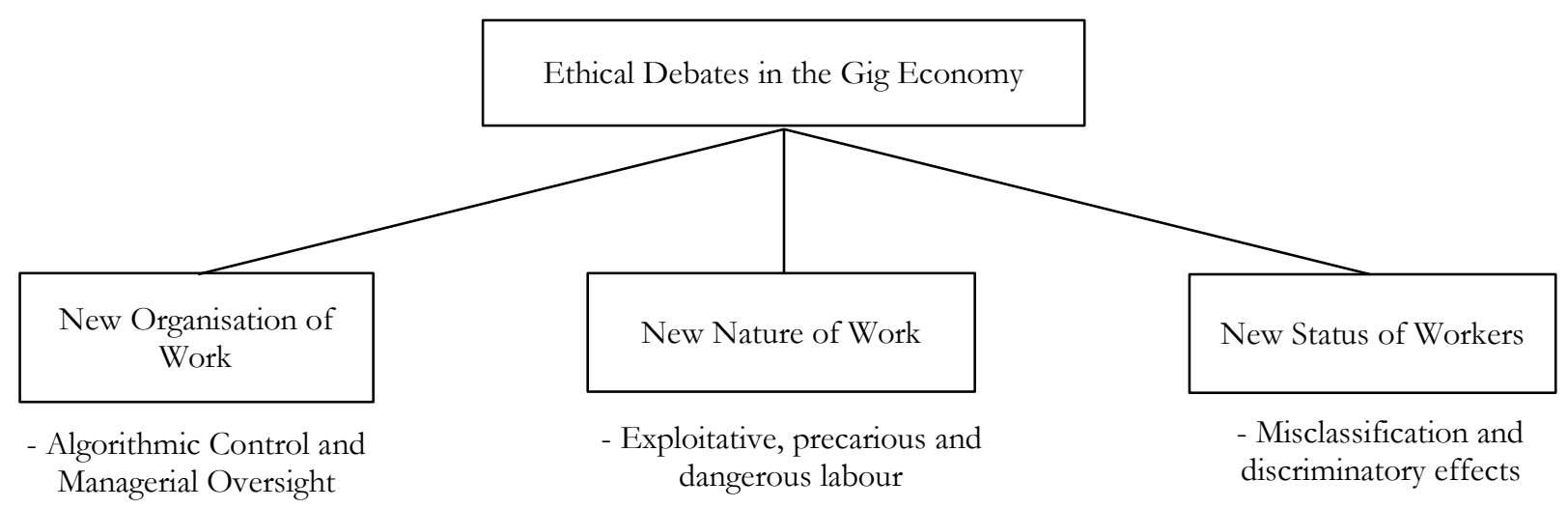

1 https:/ /ec.europa.eu/digital-single-market/en/news/final-report-high-level-expert-group-impact-digitaltransformation-eu-labour-markets 


\section{Understanding the gig economy: its scope, scale and significance}

The 'gig economy' refers to markets in short-term, on-demand, occasional, and typically task-based labour. Originating in the music industry, the term 'gig' is increasingly used to describe work in a much wider range of industries, including food and beverages, transport, education, and many more. Cost-cutting pressures following the 2008 global financial crisis significantly expanded the market in temporary, contractual labour, and thus fuelled the expansion of the gig economy (Cunningham-Parmeter 2016; Glynn 2011). Of course, short-term, on-demand work is not a new phenomenon. Workers who have long provided their services on a short-term, on-demand basis include babysitters, house cleaners, minicab drivers, temp agency workers, and other 'freelancers', especially in the creative industries. As such, the label 'gig worker' overlaps closely with labels such as 'freelancer', 'self-employed', 'independent worker', 'contingent worker' and 'non-traditional worker', amongst others.2

What distinguishes the gig economy and gig work from prior forms of short-term, occasional labour is (a combination of)

i) the greater scope and scale, embracing many more industries and workers, particularly those at lower-skill levels (Burke 2019);

ii) the mediation by, and dependence on, digital technologies, specifically digital platforms;

iii) the greater flexibility and often shorter duration (micro-tasks) of 'gig' work.

The gig economy has largely grown via mobile, app-based digital platforms, which "actively facilitate direct matching between providers and customers, on a short-term and payment by task basis" (UK Department for Business, Energy, and Industrial Strategy 2018, 4). However, unlike previous uses of digital platforms for outsourcing or procurement of project work-where information technology "facilitates the dissemination of the competition" (Finkin 2016, 604)_-gig economy platforms change the business model of work. Let us see how.

The gig economy is made up of labour-based digital platforms, like Uber (ride-sharing), Taskrabbit (DIY), and Mechanical Turk (micro work). These are two- or multi-sided markets, in which the platform acts as an intermediary matching supply (workers, e.g. Uber drivers) with demand (customers, e.g. Uber passengers) (Calo and Rosenblat 2017), enabling consumers to find a service provider directly. Labour-based digital platforms should be distinguished from assetbased platforms such as Airbnb (Balaram et al. 2017), and e-commerce platforms such as Etsy. The latter are part of the 'sharing economy' broadly defined but, as they do not provide a market 
for labour services, they are not generally included in the category of 'gig work' or gig economy platforms (Balaram et al., 2017; Farrell and Greig 2016) and we shall not include them in our analysis. 3

There are two main types of labour-based platforms: crowd-sourced, micro-work platforms and work-on-demand platforms (De Stefano 2016b). The first type of platforms crowdsource or 'cloud-source' (Finkin 2016) workers for small, online-only tasks or 'micro-tasks', such as tagging photos, screening online content, transcribing and proofreading. Examples of crowdsourced micro-working platforms include Upwork, Freelancer, and Mechanical Turk.4 Work on these platforms is performed virtually. The second type of platforms match customers with workers to carry out traditional physical work, such as taxi driving or house-cleaning. Examples include Lyft, Uber, Fiverr, and TaskRabbit. As we shall see in Section 6, these platforms tend to exert more control over gig workers than crowd-sourced micro-work platforms (Aloisi 2016).

Digital platforms create opportunities for new types of work, by deconstructing a larger project into a series of smaller, distributed, and lower-skill tasks that can be performed by workers in multiple locations (notably on 'micro-work' platforms). Furthermore, digital platforms allow workers to undertake multiple gigs with ease, sometimes simultaneously. For example, drivers (and passengers) can be registered and find work on multiple ride-sharing apps at the same time. Likewise, a worker might construct a 'full time' income from multiple, part-time gigs on different digital platforms, or use gig work to supplement their income from a (traditional) day job. Gig economy platforms leverage the transformative power of the digital (Floridi 2017) to redefine the labour market and our understanding of work and work forces.

In a similar vein, the gig economy entails a geographical redefinition of labour markets. In this regard, the distinction between crowd-work and work-on-demand gig platforms could also be cast in spatial terms, as a distinction between the delocalised and localised gig economy. Delocalised gig economy refers to services that are offered regardless of worker-requester location, as for instance on crowd-work platforms. Localised gig economy-also referred to as the 'on-demand', 'sharing' or 'peer-to-peer (p2p)' economy-facilitates services between members physically situated within a shared geographical area (Wood, Lehdonvirta, and Graham 2018).

\footnotetext{
3 The 'sharing economy' is a much broader, non-specific term describing the practice of sharing unused personal resources (such as a spare room or an underutilised car) with strangers, typically in a shared geographical area or local community. Originally conceived as a barter system, it now generally operates for-profit (European Foundation for the Improvement of Living and Working Conditions, (2017)).

4 It should be noted, however, that platforms like Upwork and Freelancer do provide a wider range of task categories than MTurk, including longer-term and higher-wage contracts encompassing task categories like data science, software engineering, and design.
} 
Whichever way(s) one may choose to categorise it, the gig economy is an umbrella concept, that covers multiple types of working arrangements and relationships, and types of work. This frustrates efforts to formulate a neat, universal definition in terms of necessary and sufficient conditions. The previous analysis should help to circumscribe the phenomenon. It leads to a characterisation of the gig economy in terms of three criteria:

i) the use of digital platforms, mechanisms and processes that

ii) enable the de/re-construction of work into smaller, distributable tasks, which in turn

iii) enables more flexible, short-term, and heterogeneous working arrangements and relationships (people can have many jobs at the same time, offering more autonomy but less security, for example).

Note that (i)-(iii) represent criteria of identification, not a definition in terms of necessary and sufficient conditions for the definition of the gig economy.5

The gig economy is expanding rapidly, geographically, in terms of market penetration, and in terms of the range of people and communities involved. However, estimating the exact scope and scale of the gig economy remains challenging. The number of people (directly) working in the gig economy is difficult to quantify, not only because of the different ways in which the gig economy and gig work can be defined and measured, but also because of the intrinsically dynamic and changeable nature of the job market itself. Data compiled by the Gig Economy Data Hub suggest that that over $25 \%$ of the US workforce participates in the gig economy in some capacityi.e. as either a supplementary (part-time) or primary (full-time) source of income-and more than $10 \%$ do so on a primary basis. 6 The exact estimates vary considerably. For example, the Federal Reserve (2018)—which adopts a broad definition of people working in the gig economy, from an occasional cleaner and babysitter to an Uber driver-reports that

"overall in 2017, 31 percent of all adults [57 millions of Americans] engaged in gig work in the month before the survey" in the US labour market alone. According to a more recent report by Gallup (2018), in 2018, 36\% workers in the US had "a gig work arrangement in some capacity" (19).

\footnotetext{
5 It is often the case that only a uniquely identifying criterion can be provided and no definition is really feasible. The difference is that the former can identify its reference uniquely without specifying its nature, for example "Alice is the woman in the corner" is a criterion of unique identification that does not define Alice. For many concepts and phenomena, we only have criteria: democracy, intelligence, love, friendship etc. In this article, we assume that "gig economy" is one of them. The reader who disagrees may still be willing to concede that, in any case, a criterion is all that is needed in this article.

6 See "How many gig workers are there?" by the Gig Economy Data Hub:

https://www.gigeconomydata.org/basics/how-many-gig-workers-are-there
} 
A survey by McKinsey Global Institute (2016)—which also adopts a broad definition encompassing any work characterized by 'independence' regardless of formal arrangementestimates that 27 percent of US workers are engaged in work of an independent nature on a primary or supplementary basis.

At the same time, the Contingent Worker Survey administered by the US Bureau of Labour Statistics (2017) reports that

"In 2017, 10.1 percent of the workforce was engaged in alternative arrangements. 3.8 percent was engaged in contingent arrangements. There was slight overlap between the two categories. About 1 percent of the workforce used apps to arrange work."

However, this survey only measures the number of American workers carrying out contingent or alternative work on a primary basis, therefore excluding 'occasional' or supplemental gig workers. Although these data should be interpreted cautiously (Jolley 2018), they remain significant.

In the UK, the RSA estimates that, in $2016 / 7,1.1$ million, or roughly $2 \%$ of the population, engaged in gig work at least once a year, and roughly $3 \%$ of the population had tried gig work at some point in their lives (Balaram et al. 2017). In this case, 'gig work' is defined as work found only on labour-based platforms. A more recent study estimates that as much as $9.6 \%$ of the UK adult population engaged in gig work (defined as 'platform work' carried out at least once a week) in 2019, and that this figure had more than doubled since 2016. The same study found that $15.3 \%$ of the UK working population reported having tried gig work at some point in their lives, and $28.3 \%$ reported seeking online platform work but not succeeding. As with the RSA's study (2017), their definition of gig work excludes asset-based platforms, such as Airbnb, and e-commerce platforms (such as eBay and Etsy).

Another way of estimating the size and scale of the gig economy is from the economic activity generated by digital labour platforms. For example, a study commissioned by the European Commission's Directorate-General for Internal Market, Industry, Entrepreneurship and SMEs (DG GROW) (Vaughan and Daverio 2016) estimated that 'collaborative economy' (sharing economy) platforms generated total gross revenues of nearly $€ 4 \mathrm{bn}$, and facilitated $€ 28 \mathrm{bn}$ worth of transactions, in the EU in 2015, a two-fold increase from 2014. To put these figures into perspective, they represent only c. $0.03 \%$ and $0.2 \%$, respectively, of EU GDP in 2015 (Eurostat 2020). Moreover, they measure economic activity in the collaborative (sharing) economy broadly defined, i.e. only online and labour-based platforms, but also asset-based $\mathrm{p} 2 \mathrm{p}$ platforms for sharing accommodation and crowd-financing, amongst others. The economic activity generated only by digital work platforms, with which this paper is concerned, is thus likely to be significantly smaller. It is noteworthy, however, that the economic output of these platforms is on a growing trajectory. 
In the US, the total value of consumer spending transactions in the "local on-demand economy" has been estimated at \$22bn for 2015; \$34bn for 2016; and \$57bn for 2017 (Ratcliffe n.d.). Whilst this represents a small share of overall economic activity, in this case too, we should take note of the growing trajectory. As Galperin observes, "online work is still nascent but has grown exponentially in recent years” (2019, 2). Indeed, the Online Labour Index (OLI) (Kässi and Lehdonvirta 2016) estimates that the use of (English-language) digital labour platforms is growing by $25 \%$ yearly, based on data about available jobs gathered periodically from platform websites (e.g. job category, employer country location, etc) and changes in web traffic. The data also indicate that, as far as English-language platforms are concerned, the US is the largest source of employers for remote gig workers, followed by the United Kingdom, Canada, India, and Australia.

All the previous reports and figures highlight that the gig economy is a significant and expanding phenomenon. As already remarked, the gig economy generates ethical challenges and a robust debate about them. The rest of the article is dedicated to the analysis of this debate.

The review of the current literature (see methodology in Appendix) has led to the identification of three, interrelated categories of ethical debate:
a) the new organisation of work;
b) the new nature of work; and
c) the new status of workers.

For the sake of simplicity, we shall use these categories to structure the discussion in the next three sections, addressing them separately even if they must be understood as intertwined.

\section{Ethical debate relating to the new organisation of work}

The key ethical concerns in this category relate to the role of gig economy platforms as mechanisms of algorithmic control and managerial oversight. Specifically, the literature examines the effects of platform-based, algorithmic reputation systems that facilitate job search, allocation and matching, and accountability between distributed workers (Pallais 2014; Ye, Gao, and Viswanathan 2014; Luca 2016). Reputation systems have long been studied for their role in facilitating trust and trade among decentralised parties (Greif 1989). Digital platforms use reputation systems as a trust mechanism to facilitate economic interactions (Diekmann et al. 2014). Reputation scores and ratings for gig workers, based on feedback from customers, are used to supervise workers and monitor the quality of their work, as well as to allocate and match workers with requesters. 
However, these systems often lead to unequal distributional outcomes. Wood et al (2019) note the presence of a "rich get richer" or Matthew effect, 7 wherein

"workers with the best scores and the most experience tended to receive more work due to clients' preferences and the platforms' algorithmic ranking of workers within search results" (64).

Further, algorithmic reputation scores facilitate a "system of control" (Granovetter 2005; Wood et al. 2019a), by which platform administrators can govern interactions between parties and exert political power on their users (Rosenblat and Stark 2016; Acemoglu, Johnson, and Robinson 2004; Wood 2018). Control stems in part from the reductive nature of reputation and rating systems, where differences in workers' identities are homogenised through the use of standardised metrics, controlled by the platform's designers and administrators. This reductive quality, combined with a skewed supply-side market on gig platforms, may give platform administrators significant power to manipulate the scoring and matching algorithms that govern the platform and influence job allocation decisions, without fear of diminishing the overall supply of workers.

This apparatus of algorithmic market control is reinforced by the system's opacity. The algorithms underpinning digital gig work platforms are typically proprietary and protected by trade secrecy laws that guard them from scrutiny by third parties. Their design and operation are usually understood only by those "on the inside" - namely the employees of the platforms whose job it is to design, optimise, and maintain these systems (Fowler 2018). Furthermore, platform administrators have no obligation to inform workers of changes to the algorithms that influence their ability to find work. As van Doorn (2017) observes, from the perspective of platform owners and administrators,

"if you intend to build your platform for maximum scalability and eventual profitability, which remain the two primary criteria for receiving venture capital, investing in equitable labor conditions will likely not be an integral part of your business model" (904).

Algorithmic control in the gig economy in this way has been likened to Taylorist forms of scientific management (Cherry 2016; Aloisi 2016), due to the extensive monitoring and measurement of worker productivity that it facilitates (Bain and Taylor 2000). Whilst Taylorist methods entail significant levels of monitoring and control throughout the working process, control in online labour platforms primarily manifests itself at the completion of a gig, in the form of consequential ratings and reputation scores. As such, it has been argued that rating and reputation systems are

7 The term indicates the reinforcement of polarisation and takes its name from the famous text in Matthew 25:29: "For to everyone who has more will be given, and he will have abundance; but from him who has not, even what he has will be taken away". 
better conceptualised as a form of "soft" managerial control (Wood et al 2019). However, whilst ratings only explicitly manifest themselves at the completion of a gig, they exert implicit control and monitoring throughout the working process, as workers are forced to manage their client relationships and shape their behaviour in order to protect against, or pre-empt, a negative rating. Further, some online labour platforms, such as Upwork, pressure workers to self-submit (through automated screenshots) to desktop monitoring and work tracking, as a way of resolving potential disputes with employers. Reputation systems also exert control by creating competition for status between workers, "a hierarchical space in which 'all participants relate to one another continuously and competitively"' (van Doorn 2017, 903).

Further ethical concerns due to algorithmic control arise from the increased scope for price discrimination on gig economy platforms. On the one hand, Chen and Sheldon (2015) find that dynamic pricing models, e.g. surge pricing on Uber, are an effective "on-demand" market intervention to increase available drivers when demand is high.s More broadly, Cramer and Krueger (2016) have found that

"UberX drivers, on average, have a passenger in the car about half the time that they have their app turned on [...] In contrast, taxi drivers have a passenger in the car an average of anywhere from 30 percent to 50 percent of the time they are working” (2-3)

These findings seem to cast a positive light on Uber and other gig economy platforms, as innovative 'disruptors' of conventional industries; more accurate price discrimination could increase market efficiency, by matching more precisely supply and demand (Rogers 2017). However, as Zwick (2018) argues, these findings do not capture the full story, particularly from the perspective of gig workers. In particular, after taking account of out-of-pocket expenses, such as for fuel and maintenance of personal vehicles, Uber drivers

"only make approximately minimum wage and potentially less [... the] ability for drivers to make more through surge pricing is dependent on a driver being able to maintain flexible schedules that further disadvantages the most economically vulnerable workers" (686).

Thus, the scope for price discrimination on algorithmic gig platforms also contributes to concerns about the precarity and insecurity of work in the gig economy, as examined further in the next section.

8 Though it would be important to acknowledge that Chen, at the time of publication, served as head of economic research for Uber. 


\section{Ethical debate relating to the new nature of work}

The main ethical issues in this category concern the nature of gig work-specifically, its flexible/precarious and menial nature - that contributes to the exploitation of gig workers. These problems inevitably overlap with the problems of misclassification of gig workers as nonemployees, resulting in weaker social and legal protection, and the outsourcing of gig work to 'lowrights' jurisdictions. These problems are examined further in Section 5.

Positive narratives of the gig economy highlight the job flexibility that it affords, wherein gig workers are given more control over the way that they conduct, pace, and schedule their work (Broughton et al. 2018). Indeed, in theory, workers should be able to log onto gig economy platforms at their choosing, and almost instantly find work. However, this narrative about flexibility is problematic, both normatively and practically.

Normatively, it presumes that flexibility is always a value in itself, ignoring that some workers in fact prefer routine, predictable and fixed-schedule employment (Manyika et al. 2016). Moreover, the same narrative presumes that flexibility is an end in itself-rather than a means to other ends, such as the ability to exercise one's own autonomy- and that it is useful and beneficial for all gig workers, even though for some it can be detrimental to their psychological well-being (Lewchuk 2017; Berger et al. 2019; Benjamin et al. 2019). Practically, flexibility of work is constrained, for example by timing of job posts, which affects particularly for workers in different time zones (De Stefano 2016b; Gupta et al. 2014), or by the competition among workers to be assigned jobs. In many cases, flexibility is not a choice of the workers, it is rather an imposed feature of gig work, which may hinder workers' well-being and rights. This became clear during the COVID-19 pandemic, when Amazon, Deliveroo and other gig economy workers continued to work-mostly out of necessity rather than choice-despite the 'lockdown' orders in many countries, endangering their health as a result.

Further, the economic downturn due to the pandemic has meant that more people in wider segments of the population have taken up work in the gig economy in order to supplement lost income (Semuels 2020).9 However, this increase in the supply of gig workers does not necessarily match the demand for such services (Spurk and Straub 2020). For example, while demand for food- and other-delivery work might have increased due to more consumers staying at home as a result of lockdowns or movement restrictions, other gig economy services, like ride-sharing, faced an oversupply of workers and undersupply of jobs. These effects have also been reported by delocalised digital platform workers in the United States (Stephany et al. 2020), who have stated

9 It is important to note that the impact of the pandemic on labour markets are not uniform either across or within countries. Germany seems to be less likely to be affected due to their short-time work scheme, and existing inequalities within national labour markets are likely to be exacerbated (Adams-Prassl et al. 2020). 
that there are fewer jobs being posted online and that existing clients are halting ongoing projects. High-demand job categories, like software development and technology, are also being affected, as the increase of labour supply outpaces the increase of labour demand. The same article also reports that workers are diversifying and bidding for more types of jobs, often below their target wage rates-even for jobs paid at below minimum wage. These findings concur with reports describing gig workers' experiences of insecurity, lack of control, and precarity (Ravenelle 2017; Schor and Attwood-Charles 2017; Tran and Sokas 2017; Halliday 2019).

Concerns about job precarity have fuelled many of the protests and industrial action by gig workers in major cities in recent years (Coca 2018; Varghese 2018; Ghaffary 2019; Carmody and Fortuin 2019; Tassinari and Maccarrone 2020). Problems related to precarious work are not new per se, they fit into a broader and long-standing critique of neoliberal capitalism (as discussed in Section 3). Key features of work in the contemporary gig economy-distribution of tasks based on casual, seasonal, or contract-based working arrangements (Deakin 2000) (Quinlan 2012)—can be found in earlier, pre-industrial eras of capitalism, though these features have been subsumed into the "standard employment relationship" in the twentieth century (Stanford 2017). However, unprecedented aspects of the nature of work in the gig economy extend the critique of labour precarity in two key ways.

First, the enhanced scope for automatic, algorithmic management and supervision on gig economy platforms, based on reputation scoring systems, increases the sustainability of precarious and casual work from the perspective of employers, and therefore its attractiveness to them (Finkin 2016). Digital gig work platforms leverage the advantages of both centralised and decentralised production, allowing "outsourcing to a dispersed crowd of workers without losing substantial control over work" (De Stefano 2016a, 468), and the maintenance of a "just-in-time workforce", or "humans-as-a-service" (De Stefano 2016b; Prassl 2018; Irani and Silberman 2013).10 This extreme commodification of human labour (Aloisi 2016; De Stefano 2016b; Wood et al. 2019b) permits an entirely new level of labour precarity.

Second, the contemporary rhetoric of the 'sharing economy', with its associated values of altruistic sharing and entrepreneurialism for the masses (Ravenelle 2017), has been (ab)used to disguise the precariousness of gig work. For instance, describing gig workers as 'microentrepreneurs' and 'neighborhood heroes' (Prassl and Risak 2016, 644) misuses the terminology of entrepreneurship to justify the intensification of neoliberal employment practices by gig platforms (Ahsan 2018). Similarly, "sharing" is cast as work and purportedly gainful economic 
activity (Cockayne 2016), and platforms seek to portray themselves "under the big tent of the 'sharing economy,' because of the positive symbolic value of sharing" (Frenken and Schor 2017, 2). As Cockayne (2016) notes, "[i]n the on-demand economy, discourse and economic practice are inter-related and mutually constitutive phenomena" (p. 80), serving to justify and reify the continuation of low-wage work while undermining efforts for positive change.

Further ethical concerns about the exploitative nature of gig work emerge from the content of the work. As we have discussed, gig economy platforms enable the deconstruction of larger projects into smaller tasks. This work is typically low-skilled and low-wage. Typical examples include micro-tasks, such as labelling data and tagging photos to train machine learning models. In some cases, this work is also risky and unsavoury, for example, viewing and labelling graphic social media content, such as child abuse videos and terrorist attacks, for content moderation purposes. There is evidence that gig workers have experienced heightened emotional stress from carrying out this work (O’Connor 2017; Roberts 2019).

On the one hand, gig work, albeit menial and potentially hazardous, generates employment for workers who may otherwise have been unemployed, or employed in even more menial and risky jobs. On the other hand, there are ethical problems relating to the unfair and unequal treatment of gig workers due to a lack of labour law protection. These problems are often worsened by the fact that gig work is often outsourced to, or 'dumped' in, low-rights jurisdictions. Some solutions have been posited to help improve the quality and conditions of gig work: mechanisms to encourage active workplace solidarity can help reduce the power asymmetries between platforms and gig workers (Tassinari and Maccarrone 2020; Irani and Silberman 2013), and/or platforms themselves can be evaluated and given ratings according to how well they perform, based on "fair work" principles (Graham et al. 2020). We focus on this debate in the next section.

\section{Ethical debate relating to the new status of workers}

The third category of ethical debates in the gig economy relates to the new status of gig workers. There are two central themes discussed in the literature: the (mis)classification of gig workers and, relatedly, discriminatory effects on gig workers. Neither problem is entirely new to the gig economy. As Finkin observes, "All advanced economies have struggled with the issue of how to distinguish between the two [employees and independent contractors]" $(2016,611)$. However, the expansion of the gig economy, and society's growing reliance on precarious work, elevates the urgency of these issues, creating the need for better solutions to protect a new kind of worker in the face of "broader phenomena such as the casualization of the workforce, the informalization 
of the formal economy and the so-called "demutualisation of risk" in modern labour markets" (De Stefano 2016b, 473). Likewise, concerns about discrimination against gig workers extends the existing debate about labour market discrimination. The next two subsections recontract the relevant debates on (mis)classification and discrimination of gig workers.

\subsection{Misclassification: technological transformation and regulatory gaps}

The changing nature and perception of work in the gig economy has challenged traditional categories of employment. As we have discussed, the flexible, on-demand and 'micro' nature of gig work, together with the heavy mediating role played by digital platforms, distinguishes gig work from many traditional forms of work. The digitally-mediated nature of work on gig economy platforms makes it easier to discount gig work as pseudo-work. Similarly, gig workers are often seen as extensions of the digital platforms, rather than workers in their own right (De Stefano 2016a). The heterogeneity of terms used to describe gig workers-for example, "taskers" (TaskRabbit), “Turkers” (Mechanical Turk) or “driver-partners” (Uber)—has further muddied the perception of gig workers.

The uncertainty over how gig workers should be classified has created room for regulatory arbitrage and ethics shirking by gig economy platforms. In particular, gig platforms have sought to avoid legal and fiscal obligations, and thus reduce operating costs, by characterising their workers as self-employed, independent contractors (Sprague 2015); even though their relationship is often closer to that of employer and employee (Prassl and Risak 2016). As a result, gig workers are left with significantly weaker legal, social and economic rights as compared to other workers performing comparable work as formal 'employees', including benefits such as overtime pay, guaranteed minimum wage, employment rights to non-discrimination and collective bargaining (unionisation), health and insurance benefits. This lack of social and legal protection increases the insecurity, instability, and vulnerability of gig workers (Logue, Josserand, and Kaine 2016; Slee 2017; Raphelson 2017).

This regulatory ambiguity enables gig platforms to eschew their legal and social obligations to gig workers, as well as their fiscal obligations to the state for payroll taxes and social security (also known as national insurance) contributions (Ruckelshaus 2008). In this regard, several scholars caution against the "deregulation mantra" advanced by many digital platforms, in which they portray themselves as neutral "technological platforms" (Uber), precisely in order to avoid the ethical, legal and social responsibilities of employers (Leighton 2016; Huws 2017; Field and Forsey 2019). The reduction of business costs due to the mis-classification of gig workers also gives gig work platforms a competitive advantage over incumbent firms (Gonzalez-Padron 2017). 
Indeed, this may "ultimately spur social dumping towards worse terms and conditions of work" (De Stefano 2016b, 481); that is, it may encourage or even force more industries to rely upon gig workers in order to reduce operating costs, and thus remain competitive. Cost-cutting pressures prompted by the 2008 financial crisis and, more recently, the economic downturn due to the COVID-19 pandemic, increase the risks of social—and ethics — dumping onto gig workers (Floridi 2019).

The digital restructuring of labour markets through gig platforms, and particularly the "enhanced possibility of outsourcing production through platforms and shedding responsibilities to workers" thus calls for a restructuring and redistribution of "risks, liabilities and protection along the production value chain" (De Stefano 2016a, 468). In this regard, two main approaches are proposed in the literature. Let us analyse them separately.

The first approach is to expand existing employment law categories, classification tests and forms of employment protection to include gig work (Pinsof 2015; Cherry 2016b; Cherry and Aloisi 2016; Cunningham-Parmeter 2016; Todolí-Signes 2017; Thomas 2017). This approach advocates a more purposive (non-literal) or functional (Prassl and Risak 2016) interpretation of existing employment laws and the employment contract, to focus on the economic reality of gig work, particularly the level of dependence of gig workers on digital platforms, the balance of bargaining power between platforms and workers, and the degree of control exercised by gig platforms. Under this approach, existing tests used to determine the existence of an employeremployee relationship could be expanded and reinterpreted to account for the new ways in which gig economy platforms exert control over gig workers, and gig workers depend economically on gig platforms (Cunningham-Parmeter 2016). The focus should "not be how much control an employer exercises, but how much control the employer retains the right to exercise" (TodolíSignes 2017,198$)$. In this regard, many gig economy platforms control the allocation and pricing of work (although on an individual level this is often determined algorithmically, based on customer reviews and ratings), the appearance of workers (some platforms, such as the takeaway food delivery app Deliveroo, mandate that workers wear branded uniforms), as well as supervise the quality of the work and enforce the termination of workers. Indeed, the "triangular relationships of gig work" (Stewart and Stanford 2017; Cunningham-Parmeter 2016) may demand a more distributed notion of employment, whereby employers' duties are shared between the platform intermediary, gig workers and end-users, with potentially more than one locus of control depending on the gig working arrangement (Prassl and Risak 2016).

The second main approach discussed in the literature focuses on developing new tests and categories of employment specifically for gig workers (Zrenner 2015; Leighton 2016; Minter 2017; 
Todolí-Signes 2017; Thomas 2017; Smith 2016). This is a more literal and legislative approach, which argues that gig work is too distinctive to fit into existing employment law frameworks. The significantly greater flexibility of gig work and the far wider geographic spread of workers on gig platforms make existing employment law protections, such as minimum wages, harder to enforce and collective bargaining harder to facilitate. Proposals under this approach include the creation of a "special labour law" (Todolí-Signes 2017) or new categories of gig worker with a limited set of labour rights, such as 'independent workers' (Harris and Krueger 2015) or 'dependent contractors' (Cherry and Aloisi 2016).

Ultimately, both approaches seek to give effect to the underlying objective of labour and employment law: to "draw a distinction between the genuinely self-employed and those requiring protection, bringing the latter within its protective scope" (Prassl and Risak 2016, 620). Better enforcement of employment laws by regulators and better efforts to educate workers about their rights are also critical to achieving this objective (Stewart and Stanford 2017, 428). These educational and enforcement dimensions can be supported by strengthening the collective bargaining rights of gig workers, for example through dedicated platforms such as Turkopticon (Irani and Silberman 2013).

\subsection{Discriminatory effects on workers}

A second set of ethical concerns discussed in the literature relates to potential discriminatory effects on gig workers. Discrimination in this sense includes differential impacts on different groups of workers, notably women and ethnic minorities, i.e. gender or race based discrimination. It also includes less favourable treatment of gig workers in low-income countries, where gig work is often 'outsourced'. Beginning with the latter, work on crowd-work or delocalised gig platforms is commonly carried out by workers in lower-income countries, particularly in the Global South, where wages are lower (at market exchange rates), working conditions inferior, and human/labour rights protections significantly weaker. According to the OLI (Kässi and Lehdonvirta 2016), over half of all gig work opportunities are posted on US platforms, with workers on these platforms predominantly located in Asia.11

This new form of outsourcing carries both benefits and ethical concerns. Outsourcing of gig work can benefit the local economy by offering employment to, and higher-wage labour

11 With the notable exception of Graham (2019) and Graham et al (2020), scholarship on the effects of the gig economy in non-Western countries remains sparse, with studies examining the ethical dimensions of the gig economy in these areas especially rare. However, it should be noted that our review focuses only on Englishlanguage scholarship (owing to the methodology used), and further selects for the explicit discussion of ethical dilemmas. 
markets for, workers in low-wage countries. Numerous international organisations have noted that the rapid growth of online labour platforms in low- and middle-income countries either has already or could potentially lead to an increase in employment and poverty reduction efforts (The Rockefeller Foundation 2013; World Bank 2015; UNDP 2019). Likewise, workers sometimes use digital labour platforms to access markets overseas that are less discriminatory or as an alternative way to access local markets, insofar that digital platforms can mask characteristics likely to result in discrimination (Graham, Hjorth, and Lehdonvirta 2017). From this perspective, digital labour platforms act as vehicles for economic and social development and could mitigate unfair discrimination. However, this interpretation is not uncontroversial. As Galperin and Greppi (2017) argue, "information frictions and communication costs reduce potential gains for workers in lower-wage countries" (7). Beerepoot and Lambregts (2015) find that, although global digital platform markets facilitate a degree of wage convergence with non-western workers earning a higher relative wage than western workers, these markets have not obviated non-skills or experience-based discrimination, for example, on the basis of nationality or gender. There is also evidence of differences in bargaining power between different groups of non-Western workers. For example, Kässi and Lehdonvirta (2016) find that workers from South-East Asia command slightly higher bargaining power as a result of higher demand than their Sub-Saharan African counterparts. Furthermore, the outsourcing of gig work to low rights and low wage jurisdictions raises concerns about ethics dumping. That is, transferring ethically questionable practices to jurisdictions in which workers have weaker bargaining power, less labour and human rights, and greater economic necessity that forces them to take on such work. Based on a survey of gig workers in non-Western countries, Wood et al (2019) find that 54\% of respondents experienced a loss of sleep at night while working to the schedules of requesters. By participating in online labour markets, gig workers in these countries experience exclusion and disconnectedness from their local contexts. As they become more separated from conventional work environments and professional membership,

"living and struggling well with the anxiety of precariousness becomes more important, and potentially fulfilling, than sustaining the illusion that, if contained and interpreted well enough, that anxiety will dissipate" (Petriglieri, Ashford, and Wrzesniewski 2019, 37)

These studies challenge the interpretation of distributed gig work as inherently liberating, highlighting the heightened negative experiences of workers in the Global South due to platform policies that fail to account for, or deal effectively with, discriminatory effects.

Ethical concerns also arise from the discriminatory effects of gig work on certain social groups, particularly women and ethnic minorities. Several studies document a gender earnings gap 
on gig platforms (Cook et al. 2018; Barzilay and Ben-David 2017; Adams-Prassl and Berg 2017), with female gig workers on some platforms earning as little as two-thirds the average hourly rate as their male counterparts (Barzilay and Ben-David 2017). Further, Galperin (2019) observes gender stereotyping in platform hiring, whereby "female candidates are less likely to be hired for male-typed jobs (e.g., software development) but more likely to be hired for female-typed jobs (e.g., writing and translation) than equally qualified male candidates".

There is also evidence of racial discrimination against gig workers. For example, AfricanAmerican workers are often given lower ratings by customers: as Rosenblat et al (2017) note, "Consumer-sourced ratings like those used by Uber are highly likely to be influenced by bias on the basis of factors like race or ethnicity." (8). Given the centrality of the reputation system for managing gig workers, discrimination of this sort can significantly affect a gig worker's prospects, including their wage and likelihood of termination (see Section 3, above). There is also evidence of racial and gender-based discrimination against consumers on gig platforms. For example, Ge et al (2016) document that African-American passengers are likely to wait longer than white passengers for rides on ride-sharing services. Racial minorities could also bear a greater burden of the "emotional labour" or "identity work" that gig workers from ethnic minorities are forced to carry out to please customers, in order to overcome their racial prejudices (Rogers 2017, 97).

From a legal perspective, discrimination on the grounds of protected characteristics, such as race and gender, is restricted by law in many countries. Typically, direct discrimination (or 'disparate treatment' in US law), due to intentional bias, is prohibited, whilst indirect discrimination (or, 'disparate impact in US law)—where a formally neutral policy has a more adverse effect on certain protected groups-is prohibited unless it can be shown to pursue a legitimate business objective. However, as discussed in Section 5.1, many gig workers are not currently protected under employment law-including rights against unfair discrimination—given that they are often mis-classified as non-employees.

The extent to which these discriminatory effects give rise to ethical harm, and the measures needed to mitigate such harm, partly depends on the underlying mechanisms for discrimination, as well as the status quo-that is, how discrimination in the gig economy compares to the 'traditional' labour market.

With regard to the underlying mechanisms for observed discriminatory effects, the findings of a gender-pay gap between gig workers are typically attributed to underlying institutional, cultural and character differences between male and female workers, rather than direct discrimination by customers or employers, based on implicit or explicit bias. In particular, female workers may have less crowd-working experience, lower educational levels, and greater domestic responsibilities than 
male counterparts (Adams-Prassl and Berg 2017; Monteith and Giesbert 2017), and different preferences for, and constraints on, where to work, and how (Cook et al. 2018). However, Barzilay and Ben-David (2017) find that the gender pay-gap persists even after controlling for several of these variables, including the number of hours worked, length of work experience, educational level and customer-feedback score.12 As such, evidence of racial discrimination against gig workers is attributed not only to underlying socio-economic and institutional factors but also the biases of customers, as reflected in customer ratings (Rosenblat et al. 2017; Leong and Belzer 2017).

With regard to the status quo, it has been argued that discrimination on digital gig platforms could be no worse than (Ge et al. 2016, 3), or potentially lower than (Smart et al. 2015; Rogers $2017,95)$, the analogue/offline context. Indeed, there is considerable evidence of discrimination in offline labour markets, such as the traditional transportation sector (Goddard, Kahn, and Adkins 2014; Belcher and Brown 2015). Moreover, the large volumes of data that gig platforms collect could allow discrimination to be detected more easily than in analogue contexts (Rogers 2017, 96). The digitally mediated nature of gig work also offers greater possibility for correcting 'algorithmic discrimination', using technical measures, for example, giving workers pseudonyms to minimise the scope for racial discrimination based on their names, or adjusting the matching algorithm to counteract potential racial or gendered bias (Calo and Rosenblat 2017).13 From this perspective, therefore, the gig economy can have less negative effects than the ordinary (non-gig) economy and so reduce ethical harm due to discrimination against workers.

\section{The EU's approach}

As our literature review highlights, the gig economy gives rise to an array of ethical challenges. The silver lining is that there is growing awareness of these challenges, as well as of the need for reform. This is evidenced by various policy initiatives relating to the gig economy at both national and supranational levels of government. We conclude this review with an analysis of a particularly significant recent initiative at the EU level. In an effort to address the challenges of the digital transformation on EU labour markets, a High-Level Expert Group (HLG), commissioned by the EU in 2019, recommended three constructive avenues for reform (Goos et al. 2019). These can be summarised as building a skilled workforce to support digitalisation of work, managing new labour relations, and creating a new contract to support digital workers.

12 The literature calls for improved structural policies, such as increased statutory parental leave and public childcare, to address gender-based discriminatory effects in the gig economy, as well as in the labour market more broadly. 13 Conversely, correcting discriminatory effects based on direct prejudice is more difficult in the offline context, given that the interactions between customers and workers are more physically than digitally mediated. 
The first of these avenues focuses on the new nature of work in the gig economy. Recommendations in this category include providing workers with a "Digital Skills Personal Learning Account" 14 that could help to reduce the lock-in effect of platform work; facilitating communities of practice to foster informal group learning; and upgrading career counselling to allow workers to adapt to a digital workplace (and by extension, the unseen algorithms that act as implicit managers).

The second avenue of reform focuses on ensuring "decent work" in the gig economy. Proposed interventions here include mitigating occupational safety and health risks, with a focus on mental health and stress; updating labour laws to equalise the treatment of standard and nonstandard work arrangements; and creating a new "Social Dialogue" between workers and other stakeholders.

The third avenue of reform focus on "preventing economic and social polarization in labour markets". Recommended reforms in this category include ensuring social protection for workers regardless of their employment status; the creation of a "Digital Single Window" to manage employment contributions and taxes for gig economy work; and redistributing the value of digital ownership by treating the data generated or provided by workers as either capital, labour or intellectual property.

On the whole, these proposals are coherent, reasonable, and feasible. In particular, they stand to address several of the ethical challenges identified in our review, particularly those relating to the exploitative nature of work in the gig economy (Section 4) and the misclassification of gig workers (Section 5). However, our review also highlights gaps in the HLG report. Specifically, the report under-addresses the ethical challenges arising from the new organisation of work (Section 3) and ethical concerns relating to discrimination and exclusion of gig workers (Sections 4 and 5). With regard to the new organisation of work, our literature review highlights the ethical risks that arise from the use of algorithmically-generated worker "reputation scores" to manage and supervise work in gig platforms. In particular, these systems can distort the allocation of work, whereby the "best" workers receive a greater and growing share of the available work. They also permit invasive and unaccountable control of the work force, and managerial stand-in.

Rather than cautioning against the use of such systems, the HLG suggests, inter alia, that the use of algorithmic systems to match workers with work could be increased, either to "better inform individual workers about their specific skill set and help them find [relevant] jobs" or to "help employers find workers that better fit their skill requirements" (Goos et al. 2019, 32). This

14 These are conceptually described as worker-owned accounts through which workers can acquire and list skill qualifications that are portable between digital platforms. 
recommendation appears to be well intended, but is ill-advised. Though the use of algorithms to "help workers understand their own skill profile" may be considered, the report fails to highlight the need for safeguards to ensure the transparency, accountability, and redressing measures for the decisions taken by algorithmic systems. This could include employing algorithmic impact assessments (Kaminski and Malgieri 2020) and/or algorithmic audits (Raji et al 2020) to ensure that the use of algorithmic systems by gig platforms is as fair and transparent as possible. 15

Furthermore, the HLG Report has little to say about the concerns of discrimination, exclusion and disconnectedness faced by gig workers, as examined in Section 5. Given that the HLG's mandate relates specifically to EU labour markets, the lack of attention to problems faced by gig workers at the Global Margins may be understandable. However, this does not justify the failure to address discrimination and exclusion faced by gig workers locally. The HLG report focuses chiefly on discrimination and exclusion faced by those with mental health conditions. Although this is an important concern, the report falls short with regard to addressing discriminatory and exclusionary practices centring on race, gender, nationality/citizenship and other sensitive personal characteristics.16 It should be expanded.

Taken together, while the HLG report certainly goes in the right direction, with clear commitments to addressing each of the challenges that it identifies, additional ethical challenges highlighted by our literature review-particularly, relating to algorithmic control, and discrimination, exclusion and disconnectedness on gig economy platforms-require further consideration.

\section{Conclusion}

In this article, we synthesised a large and rapidly growing body of work relating to the ethical challenges raised by the gig economy. Some limitations remain, our methodology (see Appendix) prioritises recent academic peer-reviewed and grey literature and centres on countries that are English-speaking, industrialised and/or in the Global North. While this approach allowed us to understand the nature of gig economy and identify the related ethical (and regulatory) problems, it also highlighted the need to focus more on the occurrences and the regulation of this phenomenon outside of the Global North, especially given the rapid adoption and usage of the

\footnotetext{
15 Greater transparency for these systems has been pushed before, in the 2016 "Frankfurt Declaration" issued by a number of North American and European labour unions, labour confederations, and worker organizations ('Frankfurt Paper on Platform-Based Work' 2016).

16 The absence of recommendations addressing gender inequality due to the gig economy is indeed explicitly acknowledged in the report (Goos et al. 2019, 29).
} 
internet and internet-enabled services in Asia and Africa (Graham 2019). In these areas, the ethical problems of gig economy are likely to have a harder negative impact on workers.

As the gig economy continues to grow, it is crucial to address adequately the complete range of ethical challenges that it poses, to ensure that this new mode of work will be more than merely tolerable, but actually may become an ethically preferable development of the market economy that is fair and equitable. The gig economy should deliver no mere flexible labour, but labour that is both flexible and preferable. We hope this review can help the debate to move further in this direction.

\section{Appendix}

Information gathering for this article was conducted in three iterative stages (Figure 2). The first was a general search for peer-reviewed articles on the gig economy with a focused time frame (between 2018 and May 2020). The motivation for doing so was to ensure that the review would first have a starting point in literature that relied on the most recent and relevant data possible, given the unstable nature of the gig economy on a policy and platform architecture level. The second stage focused the search criteria on peer-reviewed articles that explicitly acknowledged or addressed ethical concerns in the gig economy and widened the timeframe to include articles published between 2015 and May 2020. The third and final stage involved the collection of grey literature, defined here as research material produced by governmental bodies, international and local NGOs, and industry firms, which was justified given the increased amount of industry and governmental focus on how best to adapt or account for a rapidly growing economic sector. Given that the amount of grey literature on the gig economy is quickly expanding, the review focused on reports published between 2015 and May 2020 by governments, large international organisations like the International Labour Organization and several EU expert committees, as well as influential business consultancies like McKinsey Global, PwC, and Deloitte. At each stage, articles collected from different search libraries were checked and filtered for duplicate results. Articles that were initially published as conference proceedings or working papers were also omitted if a final published version was available; if not, they were retained. These same checks were carried out within and between subsequent search stages. For search results numbering over 100 articles, only the first 50 were selected. Non-English language articles $(\mathrm{N}<10)$ were omitted for this review. 
Figure 2: Data Collection Stages and Breakdown

\begin{tabular}{|l|l|l|l|l|l|l|}
\hline & $\begin{array}{l}\text { Google } \\
\text { Scholar }\end{array}$ & SSRN & $\begin{array}{l}\text { Web of } \\
\text { Science }\end{array}$ & ProQuest & $\begin{array}{l}\text { Total } \\
\text { Collected }\end{array}$ & $\begin{array}{l}\text { After } \\
\text { Filtering }\end{array}$ \\
\hline $\begin{array}{l}\text { Stage 1: } \\
\text { General "gig } \\
\text { economy" search } \\
\text { (from 2018) }\end{array}$ & $50^{*}$ & $50^{*}$ & $50^{*}$ & $50^{*}$ & 150 & 64 \\
\hline $\begin{array}{l}\text { Stage 2: } \\
\text { Focused search for } \\
\text { explicitly ethical or } \\
\text { moral discussion } \\
\text { (from 2015) }\end{array}$ & $50^{*}$ & 6 & 2 & 49 & 107 & 30 \\
\hline $\begin{array}{l}\text { Stage 3: } \\
\text { Grey literature } \\
\text { collection }\end{array}$ & $\mathrm{n} / \mathrm{a}$ & $\mathrm{n} / \mathrm{a}$ & $\mathrm{n} / \mathrm{a}$ & $\mathrm{n} / \mathrm{a}$ & 27 & 27 \\
\hline
\end{tabular}

The search for peer-reviewed journal articles used four academic databases: Google Scholar, SSRN, Web of Science, and ProQuest. Keywords for the search were split into themes and truncated (using the "**" symbol) where appropriate, to allow for the complete capturing of important phrases. Boolean operators were also used when appropriate. These themes were combined using AND operators, while keywords within themes utilized OR operators. For instance, a search from stage two of data collection would have the text: ("gig economy" OR "gig work*” OR "platform work*” OR “crowdwork*” OR “digital labo*” OR “online freelanc*”) AND ("ethic*” OR "moral*”).

\section{References}

Acemoglu, Daron, Simon Johnson, and James Robinson. 2004. 'Institutions as the Fundamental Cause of Long-Run Growth'. w10481. Cambridge, MA: National Bureau of Economic Research. https://doi.org/10.3386/w10481.

Adams-Prassl, Abi, and Janine Berg. 2017. 'When Home Affects Pay: An Analysis of the Gender Pay Gap Among Crowdworkers'. SSRN Scholarly Paper ID 3048711. Rochester, NY: Social Science Research Network. https://doi.org/10.2139/ssrn.3048711.

Adams-Prassl, Abi, Teodora Boneva, Marta Golin, and Christopher Rauh. 2020. 'Inequality in the Impact of the Coronavirus Shock: Evidence from Real Time Surveys'. SSRN Scholarly Paper ID 3594017. Rochester, NY: Social Science Research Network. https://papers.ssrn.com/abstract $=3594017$. 
Ahsan, Mujtaba. 2018. 'Entrepreneurship and Ethics in the Sharing Economy: A Critical Perspective'. Journal of Business Ethics, July. https://doi.org/10.1007/s10551-018-3975-2.

Aloisi, Antonio. 2016. 'Commoditized Workers: Case Study Research on Labor Law Issues Arising from a Set of on-Demand/Gig Economy Platforms'. Comparative Labor Law \& Policy Journal 37: 653-90.

Bain, Peter, and Phil Taylor. 2000. 'Entrapped by the "Electronic Panopticon”? Worker Resistance in the Call Centre'. New Technology, Work and Employment 15 (1): 2-18. https://doi.org/10.1111/1468-005X.00061.

Balaram, Brhmie, Josie Warden, and Fabian Wallace-Stephens. 2017. 'Good Gigs: A Fairer Future for the UK's Gig Economy'. London: Royal Society for the encouragement of Arts, Manufactures and Commerce.

https://www.thersa.org/globalassets/pdfs/reports/rsa_good-gigs-fairer-gig-economyreport.pdf.

Barzilay, Arianne Renan, and Anat Ben-David. 2017. 'Platform Inequality: Gender in the GigEconomy'. Seton Hall Law Review 47: 393-432.

Beerepoot, Niels, and Bart Lambregts. 2015. 'Competition in Online Job Marketplaces: Towards a Global Labour Market for Outsourcing Services?’ Global Networks 15 (2): 236-55. https://doi.org/10.1111/glob.12051.

Belcher, Cornell, and Dee Brown. 2015. 'Hailing While Black - Navigating the Discriminatory Landscape of Transportation'. Washington, DC: Brilliant Corners. http:/ /www.brilliantcorners.com/post/hailing-while-black.

Benjamin, Daniel J., Kristen B. Cooper, Ori Heffetz, and Miles Kimball. 2019. 'A Well-Being Snapshot in a Changing World'. AEA Papers and Proceedings 109 (May): 344-49. https://doi.org/10.1257/pandp.20191079.

Berger, Thor, Carl Benedikt Frey, Guy Levin, and Santosh Rao Danda. 2019. 'Uber Happy? Work and Well-Being in the "Gig Economy". Economic Policy, July. https://doi.org/10.1093/epolic/eiz007.

Broughton, Andrea, Rosie Gloster, Rosa Marvell, Martha Green, Jamal Langley, and Alex Martin. 2018a. 'The Experiences of Those in the Gig Economy'. Department for Business, Energy and Industrial Strategy.

https://assets.publishing.service.gov.uk/government/uploads/system/uploads/attachm ent_data/file/679987/171107_The_experiences_of_those_in_the_gig_economy.pdf. . 2018b. 'The Experiences of Those in the Gig Economy'. Institute for Employment Studies.

https://assets.publishing.service.gov.uk/government/uploads/system/uploads/attachm ent_data/file/679987/171107_The_experiences_of_those_in_the_gig_economy.pdf.

Burke, Andrew E. 2019. 'The Freelance Project and Gig Economies of the 21st Century'. London: Centre for Research on Self-Employment (CRSE).

Calo, Ryan, and Alex Rosenblat. 2017. 'The Taking Economy: Uber, Information, and Power Essay'. Columbia Law Review 117: [i]-1690.

Carmody, Pádraig, and Alicia Fortuin. 2019. "Ride-Sharing”, Virtual Capital and Impacts on Labor in Cape Town, South Africa'. African Geographical Review 0 (0): 1-13. https://doi.org/10.1080/19376812.2019.1607149.

Chen, M Keith, and Michael Sheldon. 2015. 'Dynamic Pricing in a Labor Market: Surge Pricing and Flexible Work on the Uber Platform', 19.

Cherry, Miriam A. 2016a. 'Beyond Misclassification: The Digital Transformation of Work'. Comparative Labor Law \& Policy Journal, 29.

Cherry, Miriam A. 2016b. 'Beyond Misclassification: The Digital Transformation of Work'. Comparative Labor Law \& Policy Journal 37: 577-602.

Cherry, Miriam A., and Antonio Aloisi. 2016. 'Dependent Contractors in the Gig Economy: A Comparative Approach'. American University Law Review 66: 635-90. 
Coca, Nithin. 2018. ‘The Gig Economy Workers Are Organizing’. Progressive.Org. 7 August 2018. https://progressive.org/api/content/91b44036-9997-11e8-a89e-12408cbff2b0/.

Cockayne, Daniel G. 2016. 'Sharing and Neoliberal Discourse: The Economic Function of Sharing in the Digital on-Demand Economy'. Geoforum 77 (December): 73-82. https://doi.org/10.1016/j.geoforum.2016.10.005.

Cook, Cody, Rebecca Diamond, Jonathan Hall, John A List, and Paul Oyer. 2018. 'The Gender Earnings Gap in the Gig Economy: Evidence from over a Million Rideshare Drivers'. Working Paper 24732. National Bureau of Economic Research. https://doi.org/10.3386/w24732.

Cramer, Judd, and Alan B. Krueger. 2016. 'Disruptive Change in the Taxi Business: The Case of Uber'. American Economic Review 106 (5): 177-82. https://doi.org/10.1257/aer.p20161002.

Cunningham-Parmeter, Keith. 2016. 'From Amazon to Uber: Defining Employment in the Modern Economy'. Boston University Law Review 96: 1673-1728.

De Stefano, Valerio. 2016a. 'Introduction: Crowdsourcing, the Gig-Economy and the Law'. Comparative Labor Law \& Policy Journal 37 (3): 461-70.

. 2016b. 'The Rise of the Just-in-Time Workforce: On-Demand Work, Crowdwork, and Labor Protection in the Gig-Economy'. Comparative Labor Law \& Policy Journal 37 (3): 471-504.

Deakin, Simon. 2000. 'Legal Origins of Wage Labour: The Evolution of the Contract of Employment from Industrialisation to the Welfare State'. In The Dynamics of Wage Relations in the New Europe, edited by Linda Clarke, Peter de Gijsel, and Jörn Janssen, 32 44. Boston, MA: Springer US. https://doi.org/10.1007/978-1-4615-4445-6_4.

Diekmann, Andreas, Ben Jann, Wojtek Przepiorka, and Stefan Wehrli. 2014. 'Reputation Formation and the Evolution of Cooperation in Anonymous Online Markets'. American Sociological Review 79 (1): 65-85. https://doi.org/10.1177/0003122413512316.

'Digital Jobs in Africa: Catalyzing Inclusive Opportunities for Youth'. 2013. The Rockefeller Foundation. 2013. https://www.rockefellerfoundation.org/report/digital-jobs-in-africacatalyzing-inclusive-opportunities-for-youth/.

Doorn, Niels van. 2017. 'Platform Labor: On the Gendered and Racialized Exploitation of LowIncome Service Work in the "on-Demand” Economy'. Information, Communication \& Society 20 (6): 898-914. https://doi.org/10.1080/1369118X.2017.1294194.

Easton-Calabria, Evan. 2019. 'Digital Livelihoods for People on the Move'. UNDP. https://www.undp.org/content/dam/undp/library/prosperity/economic-recoverymobility/MASTER $\% 20-\% 20$ Migrant $\% 20$ Union $\% 20$ -

$\% 20$ Digital $\% 20$ Livelihoods $\% 20$ for $\% 20$ People $\% 20$ on $\% 20$ the $\% 20$ Move.pdf.

Eurofound. 2017. 'Aspects of Non-Standard Employment in Europe'. Luxembourg: Publications Office of the European Union.

Eurostat. 2020. 'GDP and Main Components (Output, Expenditure and Income)'. 2020. https://appsso.eurostat.ec.europa.eu/nui/show.do?dataset=nama_10_gdp\&lang=en.

Farrell, Diana, and Fiona Greig. 2016. 'Paychecks, Paydays, and the Online Platform Economy: Big Data on Income Volatility'. SSRN Scholarly Paper ID 2911293. Rochester, NY: Social Science Research Network. https:// papers.ssrn.com/abstract=2911293.

Federal Reserve Board. 2018. 'Report on the Economic Well-Being of U.S. Households in 2017'. Washington, DC: U.S. Federal Reserve Board.

Field, Frank, and Andrew Forsey. 2019. 'Legalising the Gig Economy'.

Finkin, Matthew. 2016. 'Beclouded Work in Historical Perspective'. SSRN Scholarly Paper ID 2712722. Rochester, NY: Social Science Research Network. https://papers.ssrn.com/abstract=2712722.

Floridi, Luciano. 2017. 'Digital's Cleaving Power and Its Consequences'. Philosophy \& Technology 30 (2): 123-29. https://doi.org/10.1007/s13347-017-0259-1. 
2019. ${ }^{\circ}$ Translating Principles into Practices of Digital Ethics: Five Risks of Being Unethical'. Philosophy \& Technology 32 (2): 185-93. https://doi.org/10.1007/s13347-01900354-x.

Fowler, Susan. 2018. “What Have We Done?”: Silicon Valley Engineers Fear They’ve Created a Monster'. Vanity Fair. 9 August 2018.

https://www.vanityfair.com/news/2018/08/silicon-valley-engineers-fear-they-created-amonster.

'Frankfurt Paper on Platform-Based Work'. 2016. https://www.igmetall.de/download/20161214_Frankfurt_Paper_on_Platform_Based_ Work_EN_b939ef89f7e5f3a639cd6a1a930feffd8f55cecb.pdf.

Frenken, Koen, and Juliet Schor. 2017. 'Putting the Sharing Economy into Perspective'. Environmental Innovation and Societal Transitions, Sustainability Perspectives on the Sharing Economy, 23 (June): 3-10. https://doi.org/10.1016/j.eist.2017.01.003.

Galperin, Hernan. 2019. “This Gig Is Not for Women”: Gender Stereotyping in Online Hiring'. SSRN Scholarly Paper ID 3501207. Rochester, NY: Social Science Research Network. https://doi.org/10.2139/ssrn.3501207.

Galperin, Hernan, and Catrihel Greppi. 2017. 'Geographical Discrimination in Digital Labor Platforms'. SSRN Electronic Journal. https://doi.org/10.2139/ssrn.2922874.

Ge, Yanbo, Christopher R Knittel, Don MacKenzie, and Stephen Zoepf. 2016. 'Racial and Gender Discrimination in Transportation Network Companies’. Working Paper 22776. Working Paper Series. National Bureau of Economic Research. https://doi.org/10.3386/w22776.

Ghaffary, Shirin. 2019. 'Driver Strikes Didn't Break Uber — but They Showed Gig Economy Workers Are Mad'. Vox. 8 May 2019.

https://www.vox.com/recode/2019/5/8/18536993/uber-lyft-break-ride-sharing-appsbut-its-the-strongest-showing-of-gig-economy-worker-protests-yet.

Glynn, Timothy P. 2011. 'Taking the Employer Out of Employment Law? Accountability for Wage and Hour Violations in an Age of Enterprise Disaggregation'. SSRN Scholarly Paper ID 1853568. Rochester, NY: Social Science Research Network. https://papers.ssrn.com/abstract $=1853568$.

Goddard, Tara, Kimberly Kahn, and Arlie Adkins. 2014. 'Racial Bias in Driver Yielding Behavior at Crosswalks'. Psychology Faculty Publications and Presentations, April. https://doi.org/10.15760/trec.130.

Gonzalez-Padron, Tracy L. 2017. 'Ethics in the Sharing Economy: Creating a Legitimate Marketing Channel'. Journal of Marketing Channels 24 (1-2): 84-96. https://doi.org/10.1080/1046669X.2017.1347005.

Goos, Maarten, Morten Binder, Katarina Ćurković, Solveigh Hieronimus, Vassil Kirov, Vili Lehdonvirta, Karl Mcfaul, Maria Savona, Gary Shaughnessy, and Lucia Velasco. 2019. 'The Impact of the Digital Transformation on EU Labour Markets'. Luxembourg: Publications Office of the European Union.

Graham, Mark, ed. 2019. Digital Economies at the Global Margins. Cambridge, MA: The MIT Press. Graham, Mark, Isis Hjorth, and Vili Lehdonvirta. 2017. 'Digital Labour and Development: Impacts of Global Digital Labour Platforms and the Gig Economy on Worker Livelihoods'. Transfer: European Review of Labour and Research 23 (2): 135-62. https://doi.org/10.1177/1024258916687250.

Graham, Mark, Jamie Woodcock, Richard Heeks, Paul Mungai, Jean-Paul Van Belle, Darcy du Toit, Sandra Fredman, Abigail Osiki, Anri van der Spuy, and Six M. Silberman. 2020. 'The Fairwork Foundation: Strategies for Improving Platform Work in a Global Context'. Geoforum 112 (June): 100-103. https://doi.org/10.1016/j.geoforum.2020.01.023. 
Granovetter, Mark. 2005. 'The Impact of Social Structure on Economic Outcomes'. Journal of Economic Perspectives 19 (1): 33-50. https://doi.org/10.1257/0895330053147958.

Grant, Maria J., and Andrew Booth. 2009. 'A Typology of Reviews: An Analysis of 14 Review Types and Associated Methodologies'. Health Information and Libraries Journal 26 (2): $91-$ 108. https://doi.org/10.1111/j.1471-1842.2009.00848.x.

Greif, Avner. 1989. 'Reputation and Coalitions in Medieval Trade: Evidence on the Maghribi Traders'. The Journal of Economic History 49 (04): 857-82. https://doi.org/10.1017/S0022050700009475.

Gupta, Neha, David Martin, Benjamin V. Hanrahan, and Jacki O’Neill. 2014. 'Turk-Life in India'. In Proceedings of the 18th International Conference on Supporting Group Work, 1-11. GROUP '14. Sanibel Island, Florida, USA: Association for Computing Machinery. https://doi.org/10.1145/2660398.2660403.

Halliday, Daniel. n.d. 'Is There a Moral Problem with the Gig Economy?' Uehiro Centre for Practical Ethics. Accessed 5 April 2020. https://podcasts.ox.ac.uk/there-moral-problemgig-economy.

Harris, Seth D, and Alan B Krueger. 2015. 'A Proposal for Modernizing Labor Laws for TwentyFirst-Century Work: The "Independent Worker"”. Discussion Paper 2015-10. The Hamilton Project. Brookings Institution.

https://www.hamiltonproject.org/assets/files/modernizing_labor_laws_for_twenty_firs t_century_work_krueger_harris.pdf.

Huws, Ursula. 2017. 'A New Bill of Workers' Rights for the 21st Century'. London: Compass. Irani, Lilly C., and M. Six Silberman. 2013. 'Turkopticon: Interrupting Worker Invisibility in Amazon Mechanical Turk'. In Proceedings of the SIGCHI Conference on Human Factors in Computing Systems - CHI '13, 611. Paris, France: ACM Press. https://doi.org/10.1145/2470654.2470742.

'Jobs Without Borders'. 2015. Text/HTML. World Bank. 2015. https://www.worldbank.org/en/news/feature/2015/06/02/jobs-without-borders.

Jolley, David. 2018. 'Myths of the Gig Economy, Corrected'. Harvard Business Review, 30 October 2018. https://hbr.org/2018/10/myths-of-the-gig-economy-corrected.

Kässi, Otto, and Vili Lehdonvirta. 2018. 'Online Labour Index: Measuring the Online Gig Economy for Policy and Research'. SSRN Scholarly Paper ID 3236285. Rochester, NY: Social Science Research Network. https://papers.ssrn.com/abstract=3236285.

Leighton, Patricia. 2016. 'Professional Self-Employment, New Power and the Sharing Economy: Some Cautionary Tales from Uber'. Journal of Management \& Organization 22 (6): 859-74. https://doi.org/10.1017/jmo.2016.30.

Leong, Nancy, and Aaron Belzer. 2017. 'The New Public Accommodations: Race Discrimination in the Platform Economy'. SSRN Scholarly Paper ID 2687486. Rochester, NY: Social Science Research Network. https://doi.org/10.2139/ssrn.2687486.

Lepanjuuri, Katriina, Robert Wishart, and Peter Cornick. 2018. 'The Characteristics of Those in the Gig Economy'. Department for Business, Energy and Industrial Strategy. https://assets.publishing.service.gov.uk/government/uploads/system/uploads/attachm ent_data/file/687553/The_characteristics_of_those_in_the_gig_economy.pdf.

Lewchuk, Wayne. 2017. 'Precarious Jobs: Where Are They, and How Do They Affect WellBeing?' The Economic and Labour Relations Review 28 (3): 402-19. https://doi.org/10.1177/1035304617722943.

Logue, Danielle, Emmanuel Josserand, and Sarah Kaine. n.d. "The "Uberisation" of Work Is Driving People to Co-Operatives'. The Conversation. Accessed 2 August 2019. http://theconversation.com/the-uberisation-of-work-is-driving-people-to-co-operatives65333.

Luca, Michael. 2016. 'Designing Online Marketplaces: Trust and Reputation Mechanisms'. NBER Working Paper Series, 22616. https://doi.org/10.3386/w22616. 
Manyika, James, Susan Lund, Jacques Bughin, Kelsey Robinson, Jan Mischke, and Deepa Mahajan. 2016. 'Independent Work: Choice, Necessity, and the Gig Economy'. New York: McKinsey Global Institute.

https://www.mckinsey.com/ /media/McKinsey/Featured\%20Insights/Employment\% 20 and $\% 20$ Growth $/$ Independent $\% 20$ work $\% 20$ Choice $\% 20$ necessity $\% 20$ and $\% 20$ the $\% 20 \mathrm{~g}$ ig\%20economy/Independent-Work-Choice-necessity-and-the-gig-economy-Fullreport.ashx.

Minter, Kate. 2017. 'Negotiating Labour Standards in the Gig Economy: Airtasker and Unions New South Wales'. The Economic and Labour Relations Review 28 (3): 438-54. https://doi.org/10.1177/1035304617724305.

Monteith, William, and Lena Giesbert. 2017. "When the Stomach Is Full We Look for Respect": Perceptions of "Good Work" in the Urban Informal Sectors of Three Developing Countries'. Work, Employment and Society 31 (5): 816-33. https://doi.org/10.1177/0950017016650606.

O'Connor, Sarah. 2017. 'Driven to Despair — the Hidden Costs of the Gig Economy'. Financial Times, 13 September 2017. https://www.ft.com/content/749cb87e-6ca8-11e7-b9c7$15 \mathrm{af} 748 \mathrm{~b} 60 \mathrm{~d} 0$.

Pallais, Amanda. 2014. 'Inefficient Hiring in Entry-Level Labor Markets'. The American Economic Review 104 (11): 3565-99.

Petriglieri, Gianpiero, Susan J. Ashford, and Amy Wrzesniewski. 2019. 'Agony and Ecstasy in the Gig Economy: Cultivating Holding Environments for Precarious and Personalized Work Identities'. Administrative Science Quarterly 64 (1): 124-70. https://doi.org/10.1177/0001839218759646.

Pinsof, Jennifer. 2015. 'A New Take on an Old Problem: Employee Misclassification in the Modern Gig-Economy Notes'. Michigan Telecommunications and Technology Law Review 22: 341-74.

Prassl, Jeremias. 2018. Humans as a Service: The Promise and Perils of Work in the Gig Economy. Oxford University Press.

Prassl, Jeremias, and Martin Risak. 2016. 'Uber, Taskrabbit, \& Co: Platforms as Employers? Rethinking the Legal Analysis of Crowdwork'. SSRN Scholarly Paper ID 2733003. Rochester, NY: Social Science Research Network. https://papers.ssrn.com/abstract=2733003.

Quinlan, Michael. 2012. "The "Pre-Invention" of Precarious Employment: The Changing World of Work in Context'. The Economic and Labour Relations Review 23 (4): 3-24. https://doi.org/10.1177/103530461202300402.

Raphelson, Samantha. 2017. 'As The Gig Economy Grows, Advocates Raise Concerns About Workers’ Safety’. NPR.Org. 4 December 2017. https://www.npr.org/2017/12/04/568377471/as-the-gig-economy-grows-advocatesraise-concerns-about-workers-safety.

Ratcliffe, Mitch. n.d. 'Sizing the Local On-Demand Economy: 2016 - 2017 - BIA Advisory Services - Local Media Watch'. Accessed 11 April 2019. http://blog.biakelsey.com/index.php/2017/02/01/sizing-the-local-on-demandeconomy-2016-2017/.

Ravenelle, Alexandrea J. 2017. 'Sharing Economy Workers: Selling, Not Sharing'. Cambridge Journal of Regions, Economy and Society 10 (2): 281-95. https://doi.org/10.1093/cjres/rsw043.

Roberts, Sarah T. 2019. Bebind the Screen: Content Moderation in the Shadows of Social Media. New Haven: Yale University Press.

Rogers, Brishen. 2017. 'The Social Costs of Uber'. University of Chicago Law Review Online 82 (1). https://chicagounbound.uchicago.edu/uclrev_online/vol82/iss1/6. 
Rosenblat, Alex, Karen E. C. Levy, Solon Barocas, and Tim Hwang. 2017. 'Discriminating Tastes: Uber's Customer Ratings as Vehicles for Workplace Discrimination'. Policy \& Internet 9 (3): 256-79. https://doi.org/10.1002/poi3.153.

Rosenblat, Alex, and Luke Stark. 2016. 'Algorithmic Labor and Information Asymmetries: A Case Study of Uber's Drivers'. International Journal of Communication 10: 3758-84.

Ruckelshaus, Catherine. 2008. 'Labor's Wage War'. Fordham Urban Law Journal 35 (2): 373.

Schor, Juliet B., and William Attwood-Charles. 2017. 'The "Sharing" Economy: Labor, Inequality, and Social Connection on for-Profit Platforms'. Sociology Compass 11 (8): e12493. https://doi.org/10.1111/soc4.12493.

Semuels, Alana. 2020. "It's a Race to the Bottom.” The Coronavirus Is Cutting Into Gig Worker Incomes as the Newly Jobless Flood Apps'. Time, 15 May 2020. https://time.com/5836868/gig-economy-coronavirus/.

Slee, Tom. 2017. What's Yours Is Mine: Against the Sharing Economy. OR Books.

Smart, Rosanna, Brad Rowe, Angela Hawken, and Al Et. 2015. 'Faster and Cheaper: How RideSourcing Fills a Gap in Low-Income Los Angeles Neighborhoods'. BOTEC Analysis Group. https://nyuscholars.nyu.edu/en/publications/faster-and-cheaper-how-ridesourcing-fills-a-gap-in-low-income-lo.

Smith, N. Craig. 2016. 'Who's Responsible? The Ethics of the Sharing Economy'. INSEAD Knowledge. 11 November 2016. https://knowledge.insead.edu/responsibility/whosresponsible-the-ethics-of-the-sharing-economy-5034.

Sprague, Robert. 2015. 'Worker (Mis)Classification in the Sharing Economy: Trying to Fit Square Pegs into Round Holes'. ABA Journal of Labor \& Employment Law 31 (1): 53-76.

Spurk, Daniel, and Caroline Straub. 2020. 'Flexible Employment Relationships and Careers in Times of the COVID-19 Pandemic'. Journal of Vocational Behavior 119 (June): 103435. https://doi.org/10.1016/j.jvb.2020.103435.

Stanford, Jim. 2017. 'The Resurgence of Gig Work: Historical and Theoretical Perspectives'. The Economic and Labour Relations Review 28 (3): 382-401. https://doi.org/10.1177/1035304617724303.

Stephany, Fabian, Michael Dunn, Steven Sawyer, and Vili Lehdonvirta. 2020. 'Distancing Bonus or Downscaling Loss? The Changing Livelihood of US Online Workers in Times of COVID-19'. Preprint. SocArXiv. https://doi.org/10.31235/osf.io/vmg34.

Stewart, Andrew, and Jim Stanford. 2017. 'Regulating Work in the Gig Economy: What Are the Options?’ The Economic and Labour Relations Review 28 (3): 420-37. https://doi.org/10.1177/1035304617722461.

Tassinari, Arianna, and Vincenzo Maccarrone. 2020. 'Riders on the Storm: Workplace Solidarity among Gig Economy Couriers in Italy and the UK'. Work, Employment and Society 34 (1): 35-54. https://doi.org/10.1177/0950017019862954.

Thomas, Kathleen DeLaney. 2017. 'Taxing the Gig Economy'. University of Pennsylvania Law Review 166: 1415-74.

Todolí-Signes, Adrián. 2017. “The "Gig Economy”: Employee, Self-Employed or the Need for a Special Employment Regulation?’ Transfer: European Review of Labour and Research 23 (2): 193-205. https://doi.org/10.1177/1024258917701381.

Tran, Molly, and Rosemary K. Sokas. 2017. 'The Gig Economy and Contingent Work: An Occupational Health Assessment'. Journal of Occupational and Environmental Medicine 59 (4): e63-66. https://doi.org/10.1097/JOM.0000000000000977.

Varghese, Sanjana. 2018. 'Gig Economy Protests Intensify as UberEats Couriers Rile at New Rules'. Wired UK, 6 October 2018. https://www.wired.co.uk/article/ubereats-deliveroojoint-strike.

Vaughan, Robert, Raphael Daverio, Europäische Kommission, and Industrie Generaldirektion Binnenmarkt Unternehmertum und KMU. 2016. 'Assessing the Size and Presence of the Collaborative Economy in Europe’. https://doi.org/10.2873/971404. 
Wood, Alex J. 2018. 'Powerful Times: Flexible Discipline and Schedule Gifts at Work'. Work, Employment and Society 32 (6): 1061-77. https://doi.org/10.1177/0950017017719839.

Wood, Alex J, Mark Graham, Vili Lehdonvirta, and Isis Hjorth. 2019a. 'Good Gig, Bad Gig: Autonomy and Algorithmic Control in the Global Gig Economy'. Work, Employment and Society 33 (1): 56-75. https://doi.org/10.1177/0950017018785616. . 2019b. 'Networked but Commodified: The (Dis)Embeddedness of Digital Labour in the Gig Economy'. Sociology, February, 0038038519828906. https://doi.org/10.1177/0038038519828906.

Wood, Alex J., Vili Lehdonvirta, and Mark Graham. 2018. Workers of the Internet Unite? Online Freelancer Organisation among Remote Gig Economy Workers in Six Asian and African Countries'. New Technology, Work and Employment 33 (2): 95-112. https://doi.org/10.1111/ntwe.12112.

Ye, Shun, Guodong (Gordon Gao, and Siva Viswanathan. 2014. 'Strategic Behavior in Online Reputation Systems: Evidence from Revoking on EBay’. MIS Quarterly 38 (4): 1033. https://doi.org/10.25300/MISQ/2014/38.4.05.

Zrenner, Alexandra. 2015. 'The Ethics of Regulating the Sharing Economy'. The Kenan Institute for Ethics at Duke University. https://kenan.ethics.duke.edu/wpcontent/uploads/2018/01/Sharing-Economy-2015.pdf.

Zwick, Austin. 2018. 'Welcome to the Gig Economy: Neoliberal Industrial Relations and the Case of Uber'. GeoJournal 83 (4): 679-91. https://doi.org/10.1007/s10708-017-9793-8. 